\title{
Discriminating Beef Producing Countries by Multi-Element Analysis and Machine Learning
}

\author{
Elisabete A. De Nadai Fernandes \\ Yuniel T. Mazola, Márcio A. Bacchi, \\ Cláudio L. Gonzaga and Silvana R.V. Sarriés \\ Nuclear Energy Center for Agriculture, \\ University of São Paulo, Avenida Centenário 303, 13416-000 Piracicaba, SP, Brazil. \\ Gabriel A. Sarriés \\ College of Agriculture Luiz de Queiroz, \\ University of São Paulo, Avenida Pádua Dias 11, 13418-900 Piracicaba, SP, Brazil. \\ Peter Bode \\ NUQAM Consultancy, 3284 LK Zuid-Beijerland, The Netherlands.
}

Corresponding Author: Elisabete A. De Nadai Fernandes.

Copyright (C) 2021 Elisabete A. De Nadai Fernandes, et al. This is an open access article distributed under the Creative Commons Attribution License, which permits unrestricted use, distribution, and reproduction in any medium, provided the original work is properly cited.

\begin{abstract}
The growing awareness of the environmental impact of beef production is greatly influencing the consumption decision. Beef production is strongly criticized due to the remarkable environmental impact of this activity, associated with problems of deforestation, water consumption, global warming, and climate change. Despite this, livestock food products play an important role in food security, accounting for 33\% of global protein consumption. Enhancing the transparency of the beef production chain is essential to increase consumer perception about its origin, safety for consumption, environmental and human aspects. A study was undertaken to assess if beef samples from different producing countries can be distinguished from another on basis of their contents of chemical elements. Beef samples from some of the top world exporters, Brazil $\left(1^{\text {st }}\right)$, Australia $\left(2^{\text {nd }}\right)$, Argentina $\left(5^{\text {th }}\right)$, Uruguay $\left(8^{\text {th }}\right)$, and Paraguay $\left(9^{\text {th }}\right)$, were analyzed by neutron activation analysis for multi-element determination. Five machine learning algorithms, Classification and Regression Tree (CART), Multilayer Perceptron (MLP), Naive Bayes (NB), Random Forest (RF), and Sequential Minimal Optimization (SMO), were used to analyze the measurement results and classify the beef producing countries. MLP model provided the best classification performance, with an accuracy of $100 \%, 98 \%, 98 \%, 96 \%$, and $82 \%$ respectively for Paraguay, Uruguay, Australia, Argentina, and Brazil. Reducing the number of classes (each country against the remaining countries), the accuracy achieved for the Brazilian beef samples was improved to $94 \%$ without changing the performance for other countries.Multi-element compositional data and machine learning algorithms allowed for discriminating beef producing countries, providing an outlook of becoming a valuable tool for geographical origin traceability and transparency.
\end{abstract}

Keywords: Neutron activation analysis, Beef authenticity, Classification techniques, Beef exporters.

Citation: Elisabete A. De Nadai Fernandes, et al. Discriminating Beef Producing Countries by Multi-Element Analysis and Machine Learning. Advances in Artificial Intelligence and Machine Learning. 2021;1(1):1. 


\section{INTRODUCTION}

The global beef industry has become one of the largest economic businesses in the world. Beef production is forecast to increase in the coming years, consolidating the United States and Brazil as the top producing countries, responsible for $37 \%$ of the 60,572 million tons supplied in 2020 . The main traders in this market are Brazil, Australia, the United States and India, accounting for $60 \%$ of the world's beef exports in 2020 [1]. The South American beef producers Brazil, Argentina, Uruguay, and Paraguay are strengthening their market share by becoming relevant trade competitors in recent years.

Beef has a history of traditional consumption in many places around the world as an essential component of the diet. Beef consumption worldwide is expected to increase strongly in the coming years greatly influenced by factors associated with the country development status, population and economic growth, consumer purchasing power, dietary preferences dictated by culture and religion, competition from other available animal proteins, trade patterns, and market access [2]. Consumer concern towards food safety, health, environment, animal welfare, and greenhouse gas emissions can affect the beef demand growth. The COVID-19 pandemic and its socio-economical and world trade effects have introduced a new factor with impact to thebeef supply chains, beef production, and consumption patterns around the world.

Product traceability plays a fundamental role in the production chain. This is a challenge to meet the growing consumer demand for natural, healthy, and environmentally sustainable products. Nowadays, traceability in the beef supply chain is mandatorily adopted in producing countries, enabling cattle identification and tracing underpinning biosecurity and food safety, as well competitive advantage in the global market. Thereby it is important to have a traceability system based on the inherent characteristics of the animal.Most of the traceability systems implemented are focusing on consumer food safety assurance, animal health, control diseases, and market access [3].

According to TRASE (Transparency for Sustainable Economies) [4], in 2017 exports of 2.1 million tons of Brazilian beef were tracked, of which 0.92 million tons of the Cerrado biome, 0.53 million tons of the Amazon biome, 0.53 million tons of the Atlantic Forest biome, 0.09 million tons of the Pampa biome, 0.04 million tons of the Pantanal biome and 0.22 million tons of unknown origin. This traceability is based on self-declared and publicly available logistical data and official global trade data, thereby being a designative declaration. Despite the complex analyses and databases involved in the TRASE system, approximately $10 \%$ of the Brazilian beef exported did not have identification of the biome of origin. Total exports of the biomes Cerrado and Amazon (1.45 million tons) were higher than the exports from Australia (1.4 million tons), Uruguay (0.40 million tons), Paraguay ( 0.36 million tons), and Argentina (0.28 million tons), in the same year [5].

The slaughtering process may further disturb or even eliminate the traceability (and thus its origin) of the beef product as received by the consumer, despite all these efforts for identification of beef cattle and even tracing individual animals up to their origin of birth.In this sense, the chemical characteristics of beef have been used to discriminate the geographical origin $[6,7]$ and production system $[8,9]$. In this paper, we describe the performance of five mathematical models to assess if multi-element data on the composition of beef can be used to discriminate its origin from any of the producing countries in Latin America (Argentina, Brazil, Paraguay, and Uruguay) and Australia. For this study, from the ranking of the ten countries that most exported beef in 2020 [1], 5 were 
selected: Brazil ( $1^{\text {st }} ; 2,539,000$ metric tons; $23,50 \%$ of world); Australia ( $2^{\text {nd }} ; 1,476,000$ metric tons; $13,66 \%$ of world); Argentina ( $5^{\text {th }} ; 819$ metric tons; $7,58 \%$ of world $)$; Uruguay $\left(8^{\text {th }} ; 412\right.$ metric tons; $3,81 \%$ of world) and Paraguay ( $9^{\text {th }} ; 371$ metric tons; $3,41 \%$ of world).

\section{MATERIALS AND METHODS}

\subsection{Sampling}

A total of 452 authentic beef rump cap was sampled from the five beef producing countries. Samples from Argentina (62), Australia (51), Paraguay (56), and Uruguay (56), from the same production batch for each country, were received from a local beef importer. The samples from Brazil (228) were collected directly from the producing farms. The samples were vacuum-packed and kept frozen at $-20^{\circ} \mathrm{C}$ in the laboratory until processing for analysis.

\subsection{Analytical Procedure}

The rump cap after removal of the fat cap was frozen and freeze-drying for 5 days. After lyophilization, the sample was ground in a Retsch PM 400 mill with grinding jars and sintered aluminum oxide balls. For Neutron Activation Analysis (NAA),250mg analytical portions of dried samples were used. The samples were irradiated for $4 \mathrm{~h}$ at a $1.2 \times 10^{13} \mathrm{~cm}^{-2} \mathrm{~s}^{-1}$ thermal neutron flux in the IEA-R1 nuclear research reactor of the Nuclear and Energy Research Institute, Brazilian Nuclear Energy Commission (IPEN/CNEN), located in the city of São Paulo, SP. For analytical quality (trueness) control, the NIST certified reference materials RM 8414 Bovine Muscle Powder and SRM1577c Bovine Liver were analyzed. The induced activity in the samples was measured by highresolution gamma-ray spectrometry. Chemical element mass fractions were calculated using the Quantu software package [10] based on the $k_{0}$-method [11]. The final mass fractions were corrected considering the residual moisture, determined using $1 \mathrm{~g}$ analytical portion oven-dried with air circulation for 5 days at $105^{\circ} \mathrm{C}$.

\subsection{Chemometric Analysis}

The Kruskal-Wallis Comparison Test (RANOVA) was used to identify the statistically significant differences between the chemical element mass fraction of beef from different beef producing countries at a confidence level of $95 \%(\mathrm{p}<0.05)$. Principal Component Analysis (PCA) was implemented as unsupervised learning with dimensionality reduction. SAS OnDemand for Academics software was used to carry out the statistical tests.

Samples were separated into a training set ( $60 \%$ of the data set) and a test set ( $40 \%$ of the data set) to construct the Classification and Regression Tree (CART), Multilayer Perceptron (MLP), Naive Bayes (NB), Random Forest (RF) and Sequential Minimal Optimization (SMO) models. WEKA (Waikato Environment for Knowledge Analysis) software version 3.8 [12], containing a collection of machine learning algorithms for data mining tasks, was used to perform the classification tests. Mathematical details of these algorithms were reported $[13,14]$. The classification performance of 
the models was evaluated by accuracy, precision, sensitivity and specificity $[15,16]$, here defined as

$$
\begin{aligned}
& \text { Accuracy }=\frac{(T P+T N)}{(T P+T N+F P+F N)} \\
& \text { Precision }=\frac{(T P)}{(T P+F P)} \\
& \text { Sensitivity }=\frac{(T P)}{(T P+F N)} \\
& \text { Specificity }=\frac{(T N)}{(T N+F P)} \\
& \text { Where }
\end{aligned}
$$

- True Positive (TP): samples correctly classified as corresponding to a class

- True Negative (TN): samples correctly classified as not corresponding to a class

- False Positive (FP): samples misclassified as corresponding to a class

- False Negative (FN): samples misclassified as not corresponding to a class

\section{RESULTS AND DISCUSSION}

The neutron activation analysis of the beef samples resulted in mass fractions of the chemical elements $\mathrm{Br}, \mathrm{Co}, \mathrm{Cs}, \mathrm{Fe}, \mathrm{K}, \mathrm{Na}, \mathrm{Rb}, \mathrm{Se}$, and $\mathrm{Zn}$. These elements were also measured in the certified reference materials analyzed for quality control. The En Score values obtained for these elements in the certified reference materials were between -1 and 1 , corroborating the analytical quality of the results [17]. The Chi-square values for element mass fractions from Kruskal-Wallis multiple comparison tests were $<0.001$, showing the high statistical potential of all chemical elements to discriminate beef from producing countries.

TABLE 1 shows the median mass fraction of chemical elements, robust standard deviation, interquartile range, and Kruskal-Wallis multiple comparison test.Beefproducing countries marked with the same SSD in Table 1 are not statistically different $(p>0.05)$ on basis of their chemical element mass fractions. The beef samples from Paraguay have the lowest mass fraction of Co. No statistically significant difference $(\mathrm{p}>0.05)$ was found between the Co mass fractions of beef samples originating from Australia and Brazil, nor between the samples originating from Brazil, Uruguay, and Argentina. Brazilian samples showed the highest Cs mass fraction, being statistically different $(\mathrm{p}<0.05)$ from the samples of the other countries. No statistically significant difference ( $p>0.05$ ) was found between the Cs mass fractions of beef samples from Australia and Uruguay, nor between those from Argentina and Paraguay. No statistically significant difference $(p>0.05)$ was found between the Fe mass fractions of beef samples from Argentina, Australia, and Uruguay, nor between samples from Brazil and Paraguay. The samples from Paraguay showed the highest mass fraction of $K$, being statistically different $(p<0.05)$ from the other samples. No statistically significant difference $(\mathrm{p}>0.05)$ was found between the $\mathrm{K}$ mass fractions of beef samples from Brazil, Australia and Uruguay. Paraguay and Argentina presented the largest Na mass fraction, with 
Table 1: Median element mass fractions, robust standard deviation ( $\left.\mathrm{S}^{*}\right)$, interquartile range (IQR) and statistically significant difference (SSD) using the Kruskal-Wallis test.

\begin{tabular}{|c|c|c|c|c|c|c|}
\hline \multicolumn{2}{|c|}{ Analyte } & \multirow{2}{*}{$\begin{array}{c}\begin{array}{c}\text { Argentina } \\
(\mathbf{n}=\mathbf{6 2})\end{array} \\
16\end{array}$} & \multirow{2}{*}{$\begin{array}{c}\begin{array}{l}\text { Australia } \\
(\mathbf{n}=\mathbf{5 1})\end{array} \\
12\end{array}$} & \multirow{2}{*}{$\begin{array}{c}\text { Brazil (n } \\
=\mathbf{2 2 8} \text { ) }\end{array}$} & \multirow{2}{*}{$\begin{array}{c}\begin{array}{l}\text { Paraguay } \\
(\mathbf{n}=\mathbf{5 6})\end{array} \\
7\end{array}$} & \multirow{2}{*}{$\begin{array}{c}\begin{array}{c}\text { Uruguay } \\
(\mathbf{n}=\mathbf{5 6})\end{array} \\
42\end{array}$} \\
\hline $\mathrm{Br}$ & Median (mg/kg) & & & & & \\
\hline & $\mathrm{S}^{*}(\mathrm{mg} / \mathrm{kg})$ & 9 & 5 & 12 & 1 & 14 \\
\hline & IQR (mg/kg) & 12 & 7 & 5 & 2 & 19 \\
\hline & SSD & $\mathbf{B}$ & $\mathbf{B}$ & D & $\mathbf{C}$ & $\mathbf{A}$ \\
\hline \multirow[t]{4}{*}{ Co } & Median (mg/kg) & 0.011 & 0.015 & 0.013 & 0.009 & 0.012 \\
\hline & $\mathrm{S}^{*}(\mathrm{mg} / \mathrm{kg})$ & 0.004 & 0.006 & 0.031 & 0.004 & 0.003 \\
\hline & IQR (mg/kg) & 0.005 & 0.009 & 0.012 & 0.004 & 0.004 \\
\hline & SSD & B & $\mathbf{A}$ & AB & $\mathbf{C}$ & B \\
\hline \multirow[t]{4}{*}{ Cs } & Median (mg/kg) & 0.02 & 0.04 & 0.15 & 0.016 & 0.06 \\
\hline & $\mathrm{S}^{*}(\mathrm{mg} / \mathrm{kg})$ & 0.20 & 0.07 & 1.55 & 0.003 & 0.07 \\
\hline & IQR (mg/kg) & 0.04 & 0.08 & 0.12 & 0.005 & 0.03 \\
\hline & SSD & $\mathbf{C}$ & B & $\mathbf{A}$ & $\mathbf{C}$ & B \\
\hline \multirow[t]{4}{*}{$\mathbf{F e}$} & Median (mg/kg) & 100 & 105 & 83 & 91 & 94 \\
\hline & $\mathrm{S}^{*}(\mathrm{mg} / \mathrm{kg})$ & 17 & 21 & 21 & 14 & 16 \\
\hline & IQR (mg/kg) & 28 & 38 & 29 & 26 & 30 \\
\hline & SSD & $\mathbf{A}$ & $\mathbf{A}$ & B & B & $\mathbf{A}$ \\
\hline \multirow[t]{4}{*}{$\mathbf{K}$} & Median (mg/kg) & 13270 & 11489 & 12661 & 15725 & 11479 \\
\hline & $\mathrm{S}^{*}(\mathrm{mg} / \mathrm{kg})$ & 2006 & 2186 & 2279 & 2395 & 1962 \\
\hline & IQR (mg/kg) & 3756 & 3923 & 3934 & 4433 & 3686 \\
\hline & SSD & B & $\mathbf{C}$ & $\mathbf{C}$ & $\mathbf{A}$ & $\mathbf{C}$ \\
\hline \multirow[t]{4}{*}{$\mathbf{N a}$} & Median (mg/kg) & 2165 & 1721 & 2106 & 2205 & 2018 \\
\hline & $\mathrm{S}^{*}(\mathrm{mg} / \mathrm{kg})$ & 356 & 288 & 473 & 355 & 330 \\
\hline & IQR (mg/kg) & 611 & 507 & 902 & 667 & 609 \\
\hline & SSD & $\mathbf{A B}$ & $\mathbf{C}$ & B & $\mathbf{A}$ & B \\
\hline \multirow[t]{4}{*}{$\mathbf{R b}$} & Median (mg/kg) & 12 & 13 & 34 & 4.6 & 25 \\
\hline & $\mathrm{S}^{*}(\mathrm{mg} / \mathrm{kg})$ & 15 & 7 & 35 & 0.9 & 7 \\
\hline & IQR (mg/kg) & 8 & 10 & 27 & 1.5 & 10 \\
\hline & SSD & $\mathbf{C}$ & $\mathbf{C}$ & $\mathbf{A}$ & D & B \\
\hline \multirow[t]{4}{*}{ Se } & Median (mg/kg) & 0.3 & 0.7 & 0.3 & 0.24 & 0.33 \\
\hline & $\mathrm{S}^{*}(\mathrm{mg} / \mathrm{kg})$ & 0.1 & 0.2 & 0.3 & 0.08 & 0.14 \\
\hline & IQR (mg/kg) & 0.18 & 0.28 & 0.19 & 0.12 & 0.18 \\
\hline & SSD & B & $\mathbf{A}$ & B & $\mathbf{C}$ & B \\
\hline \multirow[t]{4}{*}{$\mathbf{Z n}$} & Median (mg/kg) & 184 & 156 & 164 & 178 & 178 \\
\hline & $\mathrm{S}^{*}(\mathrm{mg} / \mathrm{kg})$ & 27 & 30 & 27 & 30 & 30 \\
\hline & IQR (mg/kg) & 50 & 44 & 35 & 54 & 53 \\
\hline & SSD & $\overline{\mathbf{A B}}$ & $\mathbf{B}$ & $\mathbf{B}$ & $\mathbf{A}$ & $\mathbf{A}$ \\
\hline
\end{tabular}

no statistically significant difference $(\mathrm{p}>0.05)$ between beef samples from Argentina, Uruguay, and Brazil. The largest mass fractions of $\mathrm{Rb}$ and $\mathrm{Se}$ were found in beef samples from Brazil and Australia, respectively.

The Zn mass fraction had the least variation between all samples of beef. No statistically significant difference $(\mathrm{p}>0.05)$ was found between samples from Paraguay, Uruguay, and Argentina, nor between samples from Argentina, Brazil, and Australia. The largest $\mathrm{Br}$ mass fraction was found in beef samples from Uruguay, being statistically different from other countries. There was an increase in the $\mathrm{Br}$ mass fractions in beef from countries with longer coastline. This may be influenced 


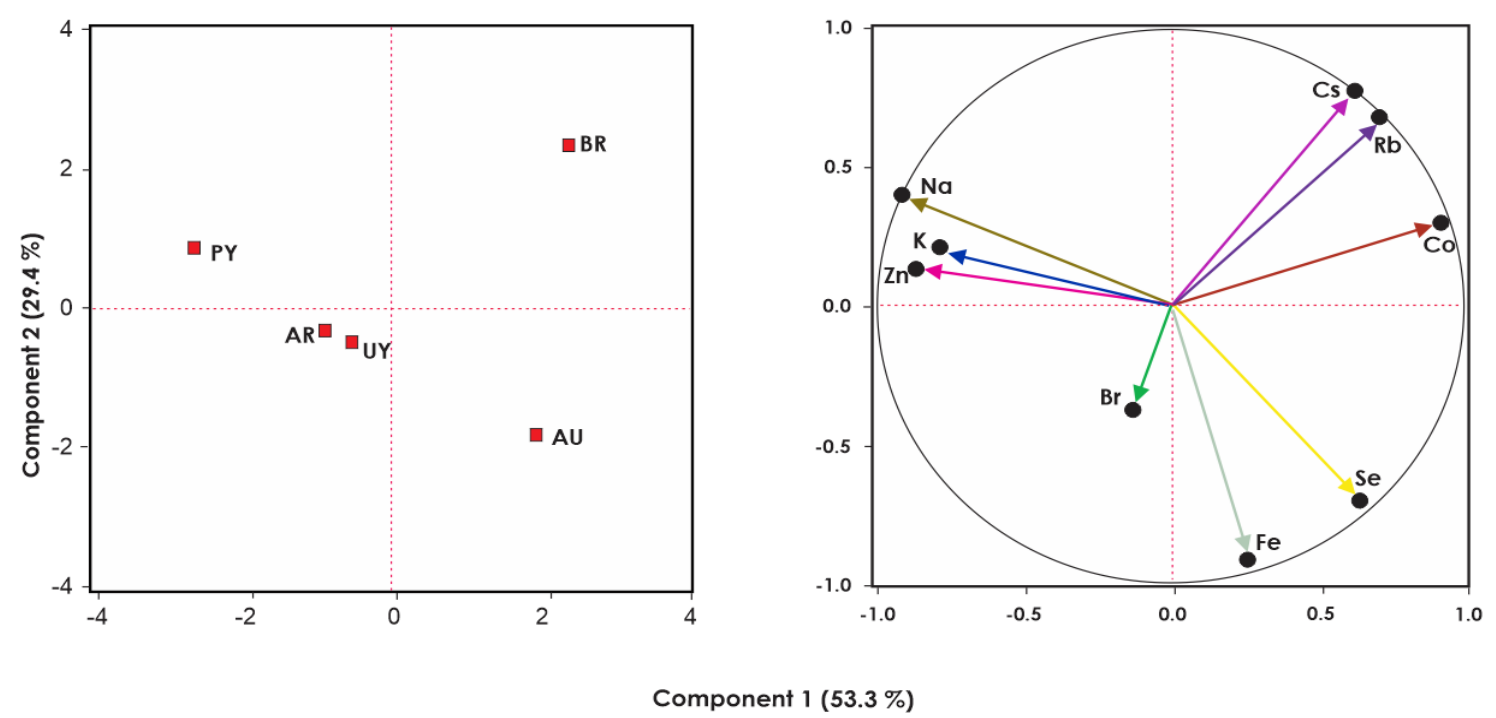

Figure 1: PCA and biplot of chemical composition of beef from five beef producing countries.

by the injection of $\mathrm{Br}$ into the atmosphere associated with marine aerosols $[18,19]$ and the burning of biomass [20],which greatly affect countries like Australia and Brazil.Despite having one of the largest coastlines, Brazilian beef samples have the lowest mass fraction of $\mathrm{Br}$, which can be explained by the huge territorial extension occupied for livestock activity and the higher concentration of cattle breeding in the central-west region [21], with the predominance of continental characteristics. The largest standard deviation of $\mathrm{Br}$ mass fractions was obtained in Brazil.

Considering that the analytical uncertainty was less than $15 \%$, this variation can be explained by the wide variety of environmental conditions for cattle breeding in Brazil. In fact, six (Br, Co, Cs, $\mathrm{Fe}, \mathrm{Na}$, and $\mathrm{Se}$ ) of the nine chemical elements studied showed the highest robust standard deviation of the mass fractions, $284 \%, 233 \%, 1013 \%, 25 \% 22 \%$, and $98 \%$, respectively. This great variability in the chemical composition of Brazilian beef made it possible to discriminate with up to $99 \%$ precision the biome in which beef was produced [6]. The Principal Component Analysis (PCA) considering $82.7 \%$ of the information, $53.3 \%$ in the Principal Component 1 (PC1), and $19.4 \%$ in the Principal Component 2 (PC2), is shown in FIGURE 1.

The formation of four groups of samples was observed depending on their characteristics, the first with beef samples from Brazil, the second with beef samples from Australia, the third with beef samples from Paraguay, and the fourth with beef samples from Argentina and Uruguay. The greatest distances were observed among the first, second, and third groups. The shortest distance was found between the third and fourth groups. The orientation and length of the vectors of each variable (mass fraction of the chemical element) were used for exploratory discrimination of beefproducing countries. Brazil had positive influence of $\mathrm{Cs}, \mathrm{Rb}$ and $\mathrm{Co}$, negative influence of $\mathrm{Br}$, and low influence of Se, Na, K, Zn, and Fe. Australia had positive influence of Se and Fe, negative influence of $\mathrm{Na}, \mathrm{K}$, and $\mathrm{Zn}$, and low influence of $\mathrm{Cs}, \mathrm{Br}, \mathrm{Rb}$, and $\mathrm{Co}$. Paraguay had positive influence of $\mathrm{Na}$, $\mathrm{K}$ and $\mathrm{Zn}$, negative influence of $\mathrm{Se}$ and $\mathrm{Fe}$, and low influence of $\mathrm{Cs}, \mathrm{Rb}, \mathrm{Br}$, and $\mathrm{Co}$. Argentina and Uruguay had positive influence of $\mathrm{Br}$, negative influence of $\mathrm{Cs}, \mathrm{Rb}$, and $\mathrm{Co}$, and low influence of $\mathrm{Se}, \mathrm{Na}, \mathrm{K}, \mathrm{Zn}$ and Fe. 


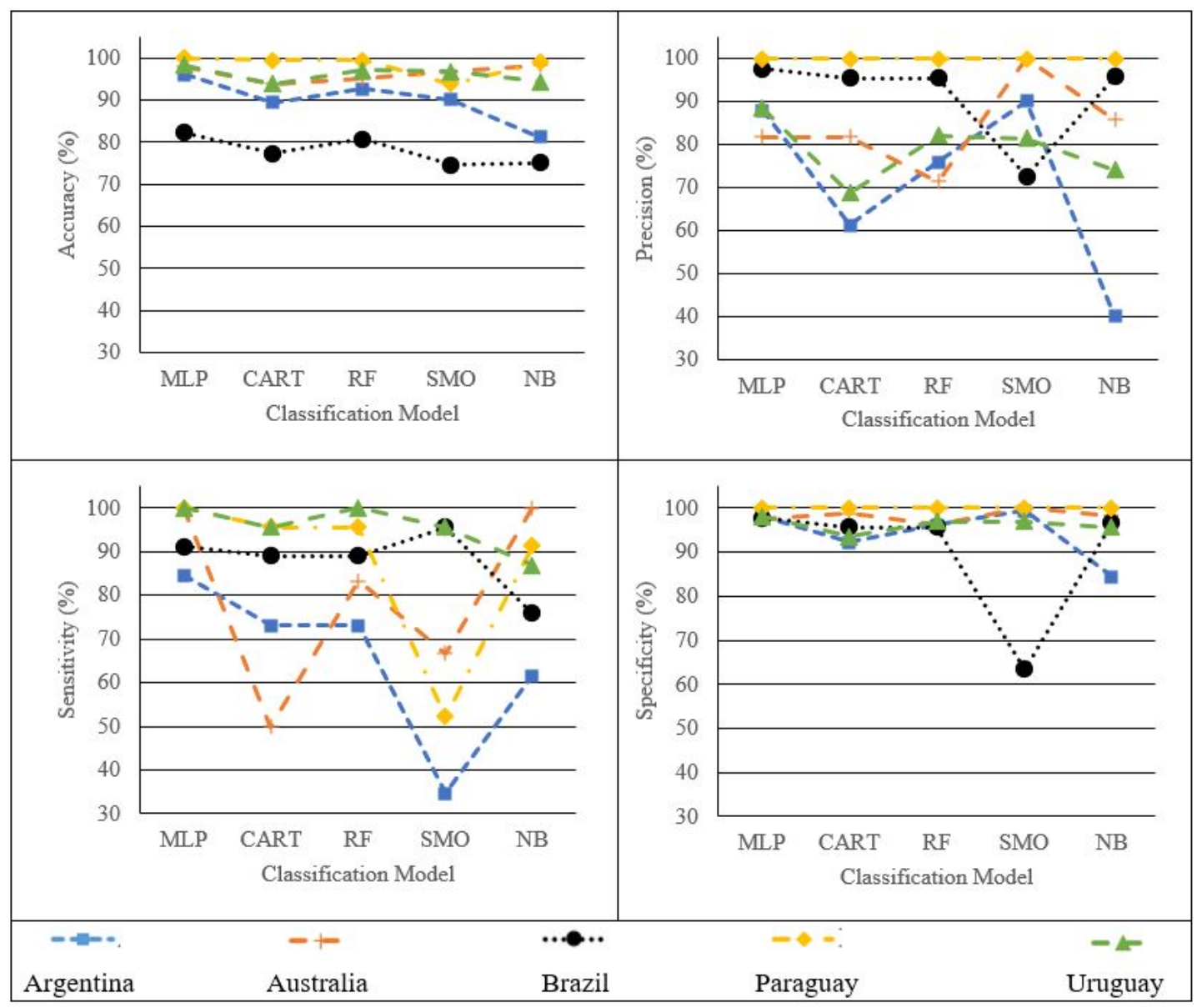

Figure 2: Performance of classification models.

The five producing countries showed statistically significant differences when compared twoby-two $(\mathrm{p}<0.0001)$ using NPMANOVA multivariate contrasts.

The five supervised machine learning algorithms (MLP, RF, CART, NB and SMO) achieved a classification accuracy of $93 \%$ (MLP), 88\% (RF), 85\% (CART), 80\% (NB), and 78\% (SMO) based on the mass fractions of $\mathrm{Br}, \mathrm{Cs}, \mathrm{Co}, \mathrm{K}, \mathrm{Fe}, \mathrm{Se}, \mathrm{Na}, \mathrm{Rb}$, and $\mathrm{Zn}$. The accuracy, precision, sensitivity, and specificity of these algorithms for each group of samples is illustrated in FIGURE2.

The best performance was obtained by MLP for discriminating samples from Paraguay, with $100 \%$ accuracy, precision, sensitivity, and specificity, with all 23 samples from the test group being correctly classified, and no sample that was not from this group was misclassified. The classification accuracy values obtained for the samples from Uruguay, Australia, Argentina and Brazil were 98\%, $98 \%, 96 \%$, and $82 \%$, respectively.A sensitivity of $100 \%$ was also obtained for the samples from Australia and Uruguay, with all samples produced in these countries being correctly classified. Less successful was the discrimination between samples from Argentina, Brazil, and Uruguay: 83 out of the 91 samples of the training set from Brazil were correctly classified, with 3 samples being classified as originating from Argentina, another 3 as originating from Uruguay, and 2 samples as 
being of Australian origin. Similarly, 22 out of 26 samples from Argentina were correctly classified and 4 misclassified: 2 as originating from Australia and the other 2 as originating from Brazil.

Table 2: Confusion matrix obtained from the classification models.

\begin{tabular}{|c|c|c|c|c|c|}
\hline \multicolumn{6}{|c|}{ MLP } \\
\hline $\mathbf{A R}$ & $\mathbf{A U}$ & BR & PY & $\mathbf{U Y}$ & $<-$ classified as \\
\hline 22 & 2 & 2 & 0 & 0 & $\mathbf{A R}$ \\
\hline 0 & 18 & 0 & 0 & 0 & $\overline{\mathbf{A U}}$ \\
\hline 3 & 2 & 83 & 0 & 3 & BR \\
\hline 0 & 0 & 0 & 23 & 0 & PY \\
\hline 0 & 0 & 0 & 0 & 23 & UY \\
\hline \multicolumn{6}{|c|}{ CART } \\
\hline $\mathbf{A R}$ & $\mathbf{A U}$ & BR & PY & $\mathbf{U Y}$ & $<-$ classified as \\
\hline 19 & 1 & 3 & 0 & 3 & $\mathbf{A R}$ \\
\hline 8 & 9 & 0 & 0 & 1 & $\mathbf{A U}$ \\
\hline 4 & 0 & 81 & 0 & 6 & BR \\
\hline 0 & 1 & 0 & 22 & 0 & PY \\
\hline 0 & 0 & 1 & 0 & 22 & UY \\
\hline \multicolumn{6}{|c|}{ RF } \\
\hline $\mathbf{A R}$ & $\mathbf{A U}$ & BR & PY & UY & $<-$ classified as \\
\hline 19 & 5 & 2 & 0 & 0 & $\mathbf{A R}$ \\
\hline 1 & 15 & 2 & 0 & 0 & $\overline{\mathbf{A U}}$ \\
\hline 4 & 1 & 81 & 0 & 5 & BR \\
\hline 1 & 0 & 0 & 22 & 0 & PY \\
\hline 0 & 0 & 0 & 0 & 23 & UY \\
\hline \multicolumn{6}{|c|}{ SMO } \\
\hline$\overline{\mathbf{A R}}$ & $\mathbf{A U}$ & BR & $\mathbf{P Y}$ & $\mathbf{U Y}$ & $<-$ classified as \\
\hline 9 & 0 & 15 & 0 & 2 & $\mathbf{A R}$ \\
\hline 0 & 12 & 6 & 0 & 0 & $\mathbf{A U}$ \\
\hline 1 & 0 & 87 & 0 & 3 & BR \\
\hline 0 & 0 & 11 & 12 & 0 & PY \\
\hline 0 & 0 & 1 & 0 & 22 & UY \\
\hline \multicolumn{6}{|c|}{ NB } \\
\hline $\mathbf{A R}$ & $\mathbf{A U}$ & BR & PY & $\mathbf{U Y}$ & $<-$ classified as \\
\hline 16 & 1 & 2 & 0 & 7 & $\mathbf{A R}$ \\
\hline 0 & 18 & 0 & 0 & 0 & $\overline{\mathbf{A U}}$ \\
\hline 20 & 2 & 69 & 0 & 0 & BR \\
\hline 2 & 0 & 0 & 21 & 0 & PY \\
\hline 2 & 0 & 1 & 0 & 20 & $\mathbf{U Y}$ \\
\hline
\end{tabular}

TABLE 2 shows the confusion matrices obtained for each of the implemented classification algorithms. The values of precision and specificity obtained for samples of beef produced in Paraguay were $100 \%$ for all the models implemented. There were no false positives by any of the models with samples from Paraguay. The CART model classified 4 samples from Brazil as coming from Argentina and 6 as coming from Uruguay, the MLP model classified 3 samples from Brazil as coming from Argentina and 3 as coming from Uruguay, the NB model classified 20 samples from Brazil as coming from Argentina, the RF model classified 4 samples as coming from Argentina and 
5 as coming from Uruguay and the SMO model classified 1 sample as coming from Argentina and 3 as coming from Uruguay. The latter may be explained by the concentration of cattle breeding in the region of the Pampa biome, shared by Argentina, Brazil, and Uruguay.

To reduce the complexity of the activation function, the number of classes was reduced from 5 to 2 , aiming at improving the classification performance $[6,22]$. Instead of using a model to classify among the five geographic origins of beef, five MLP models were generated, one for each beefproducing country.

Table 3: Confusion matrix obtained from the classification models MLP for discrimination of producing country.

\begin{tabular}{|c|c|c|}
\hline \multicolumn{3}{|c|}{ Argentina } \\
\hline AR & NAR & $<-$ classified as \\
\hline 25 & 1 & AR \\
\hline 7 & 147 & NAR \\
\hline \multicolumn{3}{|c|}{ Australia } \\
\hline AU & NAU & $<-$ classified as \\
\hline 25 & 1 & $\mathbf{A U}$ \\
\hline 7 & 148 & NAU \\
\hline \multicolumn{3}{|c|}{ Brazil } \\
\hline BR & NBR & $<-$ classified as \\
\hline 83 & 8 & BR \\
\hline 2 & 88 & NBR \\
\hline \multicolumn{3}{|c|}{ Paraguay } \\
\hline PY & NPY & $<-$ classified as \\
\hline 19 & 4 & PY \\
\hline 0 & 158 & NPY \\
\hline \multicolumn{3}{|c|}{ Uruguay } \\
\hline $\mathbf{U Y}$ & NUY & $<-$ classified as \\
\hline 23 & 0 & UY \\
\hline 4 & 154 & NUY \\
\hline
\end{tabular}

TABLE 3 shows the confusion matrix obtained for the MLP models. Discrimination of beef produced in Argentina, Australia, Brazil, Paraguay, and Uruguay was performed with accuracy values of $96 \%, 97 \%, 94 \%, 98 \%$, and $98 \%$, respectively. The greatest improvement in the classification performance was obtained for Brazilian beef, with accuracy increasing from $82 \%$ to $94 \%$. No significant variation in the classification performance was obtained for the other countries.

\section{CONCLUSION}

Machine learning applied to the multi-element composition of beef produced in Argentina, Australia, Brazil, Paraguay, and Uruguay allowed to discriminate their geographical origin. Multivariate nonparametric comparisons were highly significant $(\mathrm{p}<0,001)$, indicating the potential to track 
the origin of the beef producing country. The highest classification performance was achieved by implementing the MLP model. The highest accuracy was obtained for the Paraguay beef and the lowest for the Brazilian beef. Implementing classification models two-by-two (each country against the remaining countries), improved the accuracy values. The results show a viable strategy that can be used as a tool to improve the transparency of the world beef market.The proposed approach requires analytical data of a high degree of trueness and robustness, without any impact by the chemical matrix, and neutron activation analysis is internationally renowned for this.

\section{CONFLICT OF INTEREST}

We have no conflicts of interest to disclose.

\section{ETHICAL GUIDELINE}

We made not any examinations on a human or living creatures.

\section{ACKNOWLEDGEMENT}

The authors would like to thank the National Council for Scientific and Technological Development (CNPq) for funding sources. Yuniel Tejeda Mazola would like to thank the Coordination for the Improvement of Highereducation Personnel (CAPES) for the scholarship. Special thanks to Beef Passion, for offering all technical support during sampling campaigns.

\section{References}

[1] https://apps.fas.usda.gov/psdonline/circulars/livestock_poultry.pdf

[2] https://www.mla.com.au/globalassets/mla-corporate/prices-markets/documents/osmarkets/red-meat-market-snapshots/2021/global-beef-industry-and-trade-report.pdf

[3] Schroeder TC, Tonsor GT. "International Cattle Id and Traceability: Competitive Implications for The Us." Food Policy. 2012;37:31-40.

[4] https://supplychains.trase.earth/flows? selectedContextId=6\&toolLayout=1\&countries $=27$ \& commodities $=46 \&$ selectedColumnsIds $=0 \quad 7-1 \quad 22-2 \quad 9-3 \quad 16$

[5] https://edisciplinas.usp.br/pluginfile.php/4392168/mod_resource/content/1/Sum\%C3\%A1rio $\% 20$ ABIEC\%202017.pdf

[6] Fernandes EAN, Sarries GA, Bacchi MA, Mazola YT, Gonzaga CL, et. al. Trace Elements and Machine Learning For Brazilian Beef Traceability. Food Chem. 2020;333:127462. 
[7] Kelly SD, Heaton K, Hoogewerff J, Woolee M.Verifying the Geographical Origin of Beef: The Application Of Multi-Element Isotope And Trace Element Analysis. Food Chem. 2008;107:506-515.

[8] Logan BG, Hopkins DL, SchmidtkeLM, Fowler SM. Authenticating Common Australian Beef Production Systems Using Raman Spectroscopy. Food Control. 2021;121:107652.

[9] Logan BG, Hopkins DL, Schmidtke LM, Fowler SM. Classification of Southern Australian Grass- And Grain-Fed Beef. Food Analytical Methods. 2021.

[10] Bacchi MA, Fernandes EAN.Quantu Design and Development of a Software Package Dedicated to Ko-Standardized NAA.J RadioanalNucl Chem.2003;257:577-582.

[11] Bacchi MA, Fernandes EAN, Oliveira H. Brazilian Experience on ko StardardizedNeutron Activation Analysis. J RadioanalNucl Chem. 2000; 245:217-222.

[12] Witten IH, Frank E, Hall MA, Pal CJ. Data Mining: Practical Machine Learning Tools and Techniques. Fourth Edition ed. Morgan Kaufmann. 2016.

[13] Bishop C.Pattern Recognition and Machine Learning (Information Science and Statistics), 1st edn. 2006. corr. 2nd printing edn. Springer, New York, ed. J.K.a.B.S. Michael Jordan. 2007.

[14] Gorunescu F. Data Mining: Concepts, Models and Techniques. Springer Science \& Business Media. Vol. 12;2011.

[15] Tejeda Mazola Y, Fernandes EAN, Sarries GA, Bacchi MA, Gonzaga CL. Neutron Activation Analysis and Data Mining Techniques to Discriminate Between Beef Cattle Diets.J RadioanalNuclChem. 2019.

[16] Bisutti V, Merlanti R, Serva L, Lucatello L, Mirisola M, et. al. Multivariate and Machine Learning Approaches For Honey Botanical Origin Authentication Using Near Infrared Spectroscopy. J Near Infrared Spectrosc. 2019;27:65-74.

[17] ISO, Statistical Methods for Use In Proficiency Testing By Interlaboratory Comparison, In ISO 13528, I. Standard, Editor: Switzerland. 2015:88.

[18] Sander R, Keene W, Pszenny A, Arimoto R, Ayers G, et.al. Inorganic Bromine in The Marine Boundary Layer: A Critical Review. Atmos Chem Phys. 2003;3:1301-1336.

[19] Zhu L, Jacob DJ, Eastham SD, Sulprizio MP, Wang X, et.al. "Effect Of Sea Salt Aerosol on Tropospheric Bromine Chemistry.” Atmos Chem Phys. 2019;19:6497-6507.

[20] Yamasoe MA, Artaxo P, Miguel AH, Allen AG.Chemical Composition of Aerosol Particles From Direct Emissions Of Vegetation Fires In The Amazon Basin: Water-Soluble Species And Trace Elements. Atmos Environ.2000;34:1641-1653.

[21] http://abiec.com.br/publicacoes/beef-report-2020/

[22] Batista BL, Silva LRS., Rocha BA, Rodrigues JL, Berreta-Silva AA, et. al.MultiElement Determination in Brazilian Honey Samples By Inductively Coupled Plasma Mass Spectrometry And Estimation Of Geographic Origin With Data Mining Techniques. Food Res Int. 2012;49:209-215. 